\title{
Ultrasonographic assessment of strength of previous cesarean scar during pregnancy
}

\author{
Neeti Nisha S. Jha*, Sunita Maheshwari, Shivani Barala
}

Department of Obstetrics and Gynecology, R. N. T. Medical College, Udaipur, Rajasthan, India

Received: 16 January 2018

Accepted: 28 February 2018

\section{*Correspondence:}

Dr. Neeti Nisha S. Jha,

E-mail: neeti.nisha26@gmail.com

Copyright: (C) the author(s), publisher and licensee Medip Academy. This is an open-access article distributed under the terms of the Creative Commons Attribution Non-Commercial License, which permits unrestricted non-commercial use, distribution, and reproduction in any medium, provided the original work is properly cited.

\begin{abstract}
Background: Management of a woman who has undergone a previous cesarean section, has always been a controversial topic, with the inability to precisely confirm the integrity of the scarred lower uterine segment (LUS) being the indication of repeat cesarean section. The objective of this study is to evaluate the accuracy of ultrasonography (USG) in determining the LUS thickness in women with previous cesarean section (CS) and to assess its usefulness in predicting the risk of uterine rupture during a trial of vaginal birth.

Methods: A prospective study was conducted on 100 women between 37 to 40 weeks of gestation with a previous CS and 100 primigravidae women serving as control. Thickness of LUS was measured by transabdominal USG. The decision for mode of delivery was based purely on obstetric ground. Patients undergoing CS were considered for analysis.

Results: Mean LUS thickness was higher in the control group. Seventy-one patients of control group underwent repeat CS, in which $47(66.1 \%)$ had normal intraoperative finding. 24 (33.7\%) had abnormal LUS intraoperatively (LUS thinning). Of these, $20(28.6 \%)$ showed abnormal LUS on USG $(<5 \mathrm{~mm})$, but $4(5.6 \%)$ had normal ultrasonographic finding. Sensitivity, specificity, positive and negative predictive value of ultrasonographic evaluation were found to be $100 \%, 83.3 \%, 92 \%$ and $100 \%$ respectively.

Conclusions: Prenatal scar assessment by USG is useful in evaluation of previous cesarean scar and in most cases a near accurate evaluation was possible.
\end{abstract}

Keywords: Caesarean section, LUS, Lower uterine segment, Pregnancy, Ultrasonography, Uterine rupture

\section{INTRODUCTION}

Management of a woman who has undergone a previous cesarean section, has been a controversial topic for a long time. ${ }^{1}$ The old dictum "once a cesarean, always a cesarean" (CRAGIN, 1916) has changed now because of the awareness among obstetricians about the safety of vaginal birth in scarred uterus as well as awareness of greater maternal morbidity and increased risk of maternal mortality in cesarean birth. ${ }^{2}$

Despite this, the inability to precisely confirm the integrity of scarred lower uterine segment (LUS) becomes the indication of a repeat cesarean section. The rising rate of Cesarean Section has been the subject of much attention by medical, professional and lay communities. TOL-VBAC (Trial of labor - vaginal birth after cesarean) has been increasingly supported by the medical community because approximately 55-60\% CSections are repeat procedures. ${ }^{3}$ The advantages of vaginal delivery include decreased maternal and neonatal morbidity and mortality, and also decreased hospital stay and cost.

When a woman has had a cesarean section, her uterus has a scar on it. This scar may not be as tough as the 
surrounding muscle. Because of the stretching of the muscle during pregnancy or the strong contractions of labor, the old cesarean scar might not stand the strain of labor and it becomes thin or begins to separate. When it does, it is called 'scar dehiscence'. Rarely, the scar opens and extends into other parts of uterus. This is called as 'uterine rupture' and is a serious risk to both mother and baby. Because of this risk, repeat elective cesarean sections are being performed on women with previous cesarean section.

The rupture of caesarean scar is potentially devastating complication of trial of vaginal delivery which increases maternal and perinatal morbidity and mortality. ${ }^{4}$ There is a need to assess the integrity of uterine scar and risk factors before planning for trial of vaginal delivery.

According to RCOG guidelines, October 2015, Planned VBAC is appropriate for and may be offered to the majority of women with a singleton pregnancy of cephalic presentation at $37+0$ weeks or beyond who have had a single previous lower segment caesarean delivery, with or without a history of previous vaginal birth except for women with previous uterine rupture or classical caesarean scar and in women who have other absolute contraindications to vaginal birth that apply irrespective of the presence or absence of a scar (e.g. major placenta praevia). ${ }^{5,6}$

In women with complicated uterine scars, caution should be exercised, and decisions should be made on a case-bycase basis by a senior obstetrician with access to the details of previous surgery.

Many authors have published reports on trial of labor in a scarred uterus but only a few could establish any suitable method for evaluation of the lower uterine scar. ${ }^{4}$

Ultrasound is one these methods by which we can detect any type of defect in the integrity of scarred lower uterine segment. ${ }^{7,8}$ Hence a large number of women are added every year to the group who are potential candidates for a trial of labor for vaginal birth after cesarean section.

On ultrasound the normal lower uterine segment is a twolayered structure that consists of a superficial very echogenic layer i.e. outer myometrium juxtaposed to bladder and a deep less echogenic layer i.e. inner myometrium and decidualised endometrium.

Normally as the lower uterine segment develops the ultrasonographic resolution of the layers changes, with further thinning the myometrial layer becomes less welldefined. ${ }^{8,9}$ A sonographically identifiable window or defect develops when the myometrial layer is severely attenuated or lost and the peritoneal reflection and the outermost layers remain.

The last 4-5 decades have witnessed an increasing number of pregnancies following previous caesarean section, as a consequence of which there is an increased likelihood of pregnancies with scar rupture. ${ }^{10}$

In past hysterosalpingography (HSG) was the method of choice to diagnose strength of scar but is no longer popular because of the invasiveness, and exposure to radiation. ${ }^{11-13}$

Monitoring of scarred lower uterine segment by ultrasonography has several attractive features including non- invasive nature, rapid to perform, no exposure to radiation, repeat test on the same patient possible.

The present study has been undertaken to explore usefulness of ultrasonographic examination in evaluation of the lower uterine segment scar in cases of previous cesarean section and thus provide information of value in deciding management of such a case.

\section{METHODS}

It was a prospective observational hospital-based study conducted in the department of obstetrics and Gynecology, RNT Medical College, Udaipur between January 2015 to May 2016.

Data collection was done in woman attending the antenatal clinic in Panna Dhaya Rajkiya Mahila Chikitsalaya, associated with RNT Medical College, Udaipur.

The study compromised of two groups.

- Group A- It included 100 cases with previous cesarean section, further divided into (A1 - 80 cases with previous one LSCS, A2 - 20 cases with previous two LSCS).

- Group B - It included 100 primigravidae cases without any obstetrics complications serving as control.

The women in both groups were selected by simple random sampling and followed up to the time of delivery.

\section{Exclusion criteria}

- Multiple gestation

- Placenta praevia

- Polyhydramnios

- Hydrocephalic fetus

- Patients in labor

Transabdominal USG of LUS was performed during the third trimester of pregnancy preferably as close to the expected date of delivery as possible. However, no scans were performed in patients in labor. Measurement of the thickness of anterior wall of lower uterine segment both in longitudinal and transverse section were taken at three points over the scar. An average of these was taken to be the thickness of lower uterine segment. 
The total population was divided into three ultrasonographic criteria laid down by Michael WH. ${ }^{9}$

- $\quad$ Class I - Thickness of lower uterine segment $>5 \mathrm{~mm}$. Symmetrical lower uterine segment, no wedge defect, no ballooning in lower uterine segment. This was considered normal finding

- Class II - Thickness of lower uterine segment 3$5 \mathrm{~mm}$. There may or may not be wedge defect and ballooning, if present then of less degree. Slight asymmetry in lower uterine segment may be present. This was considered as potentially pathologic finding.

- Class III - Thickness of lower uterine segment $<3 \mathrm{~mm}$, had asymmetrical lower uterine segment, comparative high degree of ballooning and wedge defect. This was considered as pathologic finding.

Detailed history including age, parity, gestational age, socio economic status, antenatal care during pregnancy, chief complaints and duration with special emphasis on pain at previous scar site and associated medical disorder were taken. In obstetric history number of previous delivery, abortion, type of delivery, indication of previous cesarean section was taken as per proforma attached.

After ultrasonography, patients were followed up to the time of delivery whether delivered by LSCS or by vaginal route. Those delivered by LSCS were considered for final analysis.

The decision for a repeat LSCS or trial of labor was not dependent on the ultrasonographic findings but entirely based upon the treating obstetrician's evaluation.

Status of lower uterine segment was noted at the time of operation by the obstetrician performing the cesarean section. On the basis of this observation, patients were divided into three criteria laid down by Fukuda M. ${ }^{14}$

- Grade I - No thinning of lower uterine segment

- Grade II - Thinning and loss of continuity of lower uterine segment but fetal hair not visible

- Grade III - Thinning of lower uterine segment and fetal hair visible or window defect i.e. fetal parts could be seen through lower uterine segment.

The ultrasonographic and operative findings were considered for analysis.

\section{RESULTS}

In the study group, (58\%) were from the age group 26-30 years (Mean 27.27 \pm 4.10 ) with $56 \%$ being Para 1 . Majority of patients in study group were from middle and high socioeconomic status i.e. $50 \%$ and $36 \%$ respectively and booked i.e. 84\%. Mean gestational age was 38.51 weeks. Most patients $(60 \%)$ had last delivery interval of more than 2 years. 11 patients had last delivery within 1 year, of which 10 (6 had Grade II, 4 had grade III LUS) had abnormal intraoperative findings.

On ultrasonographic assessment, Mean LUS thickness of study group (7.88mm) was less than control group (8.92), and this value was statistically significant $(\mathrm{p}<0.05)$. Out of 100 patients of study group A, LUS thickness was $<5 \mathrm{~mm}$ in 20 patients i.e. $20 \%(3-5 \mathrm{~mm}$ in 14 patients and $<3 \mathrm{~mm}$ in 6 patients) and $>5 \mathrm{~mm}$ in 80 patients. Asymmetrical scar was found in $18(18 \%)$ patients (mild asymmetry in 12 patients, moderate to severe in 6 patients) Wedge or ballooning defect was found in 16 patients (mild defect in 12 patients, severe in 4 patients). However, thickness of lower uterine segment was the main criteria to classify scar. Overall, in study group A, $80 \%$ patients had class I, $14 \%$ of patients had class II and $6 \%$ patients had class III LUS (Table 1).

Table 1: Ultrasonographic classes of LUS.

\begin{tabular}{|c|c|c|c|c|c|c|}
\hline \multirow{2}{*}{$\begin{array}{l}\text { Ultrasonographic } \\
\text { class of LUS }\end{array}$} & \multicolumn{2}{|c|}{ Group $\mathbf{A}_{1}$} & \multicolumn{2}{|c|}{$\begin{array}{l}\text { Group } \\
\mathbf{A}_{2}\end{array}$} & \multicolumn{2}{|c|}{$\begin{array}{l}\text { Total }\left(\mathbf{A}_{1}\right. \\
\left.+\mathbf{A}_{2}\right)\end{array}$} \\
\hline & No. & $\%$ & No. & $\%$ & No. & $\%$ \\
\hline Class I & 66 & 82.5 & 14 & 70 & 80 & 80 \\
\hline Class II & 10 & 12.5 & 4 & 20 & 14 & 14 \\
\hline Class III & 4 & 5 & 2 & 10 & 6 & 6 \\
\hline Total & 80 & 100 & 20 & 100 & 100 & 100 \\
\hline
\end{tabular}

In group $\mathrm{A}_{1}$, out of 80 patients with previous one cesarean section, $52(65 \%)$ patients had repeat cesarean section. Elective cesarean was done in $25 \%$ of cases and emergency in $40 \%$ of cases. A total 28 patients (35\%) had vaginal delivery. Most common indication for repeat LSCS was scar tenderness (23.1\%) (Figure 1). In group $\mathrm{A}_{2}$, out of 20 patients with previous 2 cesarean section, 19 patients $(95 \%)$ had repeat cesarean section. Elective cesarean was done in $60 \%$ of cases and emergency in $35 \%$ cases. Only one patient was delivered by vaginal route, as she was admitted in late labour. Over all, in study group, $71 \%$ of patients underwent cesarean section and their operative findings were used for analysis.

Table 2: Assessment of intraoperative lower uterine segment.

\begin{tabular}{|c|c|c|c|c|c|c|}
\hline \multirow{2}{*}{ Grade } & \multicolumn{2}{|c|}{ GroupA $_{1}$} & \multicolumn{2}{|c|}{ Group $\mathbf{A}_{2}$} & \multicolumn{2}{|c|}{ Total $\left(\mathbf{A}_{1}+\mathbf{A}_{2}\right)$} \\
\hline & No. & $\%$ & No. & $\%$ & No. & $\%$ \\
\hline Grade I & 36 & 69.2 & 11 & 57.9 & 47 & 66.1 \\
\hline Grade II & 12 & 23.1 & 6 & 31.6 & 18 & 25.3 \\
\hline Grade III & 4 & 7.7 & 2 & 10.5 & 6 & 8.4 \\
\hline Total & 52 & 100 & 19 & 100 & 71 & 100 \\
\hline
\end{tabular}

In group $A_{1}$, out of 52 patients, $36(69.2 \%)$ had normal finding (grade I) and $16(30.8 \%)$ had abnormal finding which included $12(23.1 \%)$ from grade II and $4(7.7 \%)$ from grade III. In group $\mathrm{A}_{2}$, out of 19 patients, $11(57.9 \%)$ had normal findings and $8(42.1 \%)$ had abnormal finding which included 6(31.6\%) from grade II and 2 (10.5\%) from grade III. In the whole study group, 47 patients 
(66.1\%) had normal intra operative lower uterine segment (grade I) and $24(33.7 \%)$ had abnormal LUS which comprised of $18(25.3 \%)$ from grade II and 6(8.4\%) from grade III (Table 2).

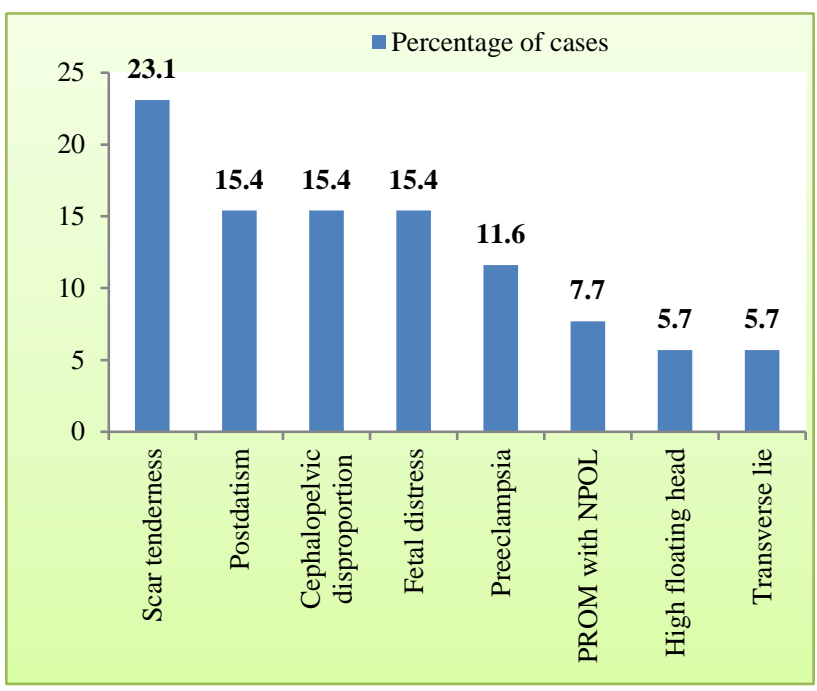

Figure 1: Indication of cesarean section of study group A.
Out of 71 patients in study group who underwent cesarean section, 47 patients (65.7\%) had normal intraoperative findings. All these patients also had normal ultrasonographic findings. Eighteen patients $(25.7 \%)$ had grade II LUS. Out of these, 14 patients had class II LUS on ultrasonography done during antenatal period but in contrast 4 patients $(5.7 \%)$ had normal class I LUS.

Six patients (8.6\%) had grade III LUS. All these patients had corresponding finding on ultrasonography (Table 3 ).

Thus, incidence of defective LUS during operation was $34.3 \%(25.7+8.6 \%)$ but defective LUS diagnosed during ultrasonography in repeat cesarean patients was $28.6 \%$. Four patients with good healing on ultrasonography who had a cesarean section had grade II scars at operation. This might be due to the interval between ultrasonographic examination (around $38^{\text {th }}$ week of gestation) and cesarean section $\left(39-40^{\text {th }}\right.$ week of gestation).

On the other hand, no patient with apparent poor healing had grade I scar at operation. Scar dehiscence and uterine rupture whether partial or complete was not found in any patient. There were no neonatal deaths. All infants born were healthy.

Table 3: Ultrasonographic Vs intraoperative LUS.

\begin{tabular}{|c|c|c|c|c|c|}
\hline \multirow{2}{*}{ Ultrasonographic finding } & \multirow{2}{*}{ No. of patients } & \multirow{2}{*}{$\begin{array}{l}\text { Percentage } \\
\text { of total }\end{array}$} & \multicolumn{3}{|c|}{ Intraoperative finding } \\
\hline & & & Grade I & Grade II & Grade III \\
\hline Class I & 51 & 71.4 & $47(65.7 \%)$ & $4(5.6 \%)$ & - \\
\hline Class II & 14 & 20 & - & $14(20 \%)$ & - \\
\hline Class III & 6 & 8.6 & - & - & $6(8.6 \%)$ \\
\hline Total & 71 & 100 & $47(65.7 \%)$ & $18(25.7 \%)$ & $6(8.6 \%)$ \\
\hline
\end{tabular}

Sensitivity and specificity of ultrasonography in detecting abnormal LUS according to present study was $83.33 \%$ and $100 \%$ respectively. Positive predictive value and negative predictive value of ultrasound in detecting abnormal LUS in our study was $100 \%$ and $92 \%$ (p value $<0.0001)$ making it highly significant.

\section{DISCUSSION}

Trial of vaginal birth after LSCS has been a topic of much debate in the past few decades. Various researchers have looked into factors which could determine the outcome of labour. Ultrasonography is one such useful tool used to measure the thickness of LUS and predict the outcome of labour. Irrespective of whether transabdominal or transvaginal route, the measured thickness at a particular cut-off value had a high negative and positive predictive value in predicting scar rupture. ${ }^{1}$ Thus the patients with thick lower uterine scar are less likely to have a scar dehiscence/rupture, similarly, patients with a thin LUS are more likely to rupture.
Table 4: Comparative study of defect by various authors.

\begin{tabular}{|lll|}
\hline Author & $\begin{array}{l}\text { Defective } \\
\text { LUS by USG } \\
(\%)\end{array}$ & $\begin{array}{l}\text { Defective LUS } \\
\text { intraoperative } \\
(\%)\end{array}$ \\
\hline Fukuda et al $^{16}$ & 23.3 & 30 \\
\hline Rozenberg et al $^{11}$ & 29 & 40 \\
\hline Cheung et al $^{19}$ & 13 & 28.6 \\
\hline Thomas A et al $^{1}$ & 9.1 & 8.75 \\
\hline Sushma VD et al & 35 & \\
\hline Present study & 28.6 & 34.3 \\
\hline
\end{tabular}

Sen et al compared between TAS and transvaginal sonography in measuring LUS thickness with high correlation of $96 \%$ between the two. ${ }^{15}$ The critical cut-off value for safe LUS thickness was $2.5 \mathrm{~mm}$ with sensitivity, specificity, NPV and PPV of 90.9\%, 84\%, 95.5\% and $84 \%$ respectively. In this study the PPV and NPV was $100 \%$ and $92 \%$ respectively. Sensitivity and specificity in detecting abnormal LUS according to present study was 
$83.33 \%$ and $100 \%$ respectively, which is comparable to Sen et al. ${ }^{12}$

In a prospective study by Cheung, the mean age of the women in the cesarean group maternal was 30.5 \pm 4.2 years and the mean LUS thickness in the cesarean group was $1.9 \pm 1.4 \mathrm{~mm} .^{16}$ Although the difference between the cesarean and nullipara control LUS thickness failed to reach statistical significance, it achieved significance in patients with more than one previous delivery (both vaginal and cesarean). Cheung reported $100 \%$ sensitivity and $90 \%$ specificity. ${ }^{16}$

The finding of difference between control and study groups is similar to those of Gotoh et al and Quereshi et al i.e. LUS was thinner in women with previous cesarean section than in primiparous women. ${ }^{17,18}$

Rozenberg et al, found that LUS thickness correlated inversely with the risk of rupture and concluded that thickness more than $3.5 \mathrm{~mm}$ is protective against rupture. ${ }^{8}$ Although the sensitivity and positive predictive value of the thin segment for a defective scar were low, the negative predictive value of the thick segment was high.

The difference between defective LUS determined by USG and that seen during operation are comparable in our study as well as others (Table 4). The risk of uterine rupture in the presence of a LUS defect, whether identifiable sonographically, is unknown. Also, the cutoff value at which an extremely thin LUS on sonographic examination can predispose to a high risk of uterine rupture has yet to be identified. This obviously could not be determined in this study and, in our opinion, was unable to be determined in previously reported studies because of the inconsistency in the measuring technique and the method used to diagnose uterine rupture. ${ }^{19}$

Michaels et al, instead of just measuring the thickness, described the sonographic appearances of the LUS by its symmetry, thickness, movement, ballooning, and the presence of a wedge defect and divided these findings into 3 classes to assist in identifying uterine defects. ${ }^{9}$ Present study used the classification proposed by Michael et al.

\section{CONCLUSION}

Although ultrasonography appears to be a promising tool for assessing the strength of a previous cesarean scar, our study sample was small and non-blinded, further largescale studies are needed to solidify its regular usage for giving trial of labour. Also, it is important to note that there are a number of other factors which lead to scar dehiscence or scar site uterine rupture, which needs to be kept in mind. Larger scale studies are needed to make ultrasonographic LUS measurement a routine in the antenatal care of women with a previous cesarean section.

Funding: No funding sources
Conflict of interest: None declared

Ethical approval: The study was approved by the Institutional Ethics Committee

\section{REFERENCES}

1. Thomas A, Rebekah G, Vijayaselvi R, Jose R. Transvaginal Ultrasonographic Measurement of Lower Uterine Segment in Term Pregnant Patients with Previous Cesarean Section. Open J Obstet Gynecol. 2015;5:646-53.

2. Verma U, Chandra M, Nagrath A, Singh S, Agrawal R. Assessment of Cesarean Section Scar Strength: Still A Challenge. 2014;24(10).

3. Bujold E, Jastrow N, Simoneau J, Brunet S, Gauthier RJ. Prediction of complete uterine rupture by sonographic evaluation of the lower uterine segment. Am J Obstet Gynecol. 2009 Sep 1;201(3):320-e1.

4. Sen S, Malik S, Salhan S. Ultrasonographic evaluation of lower uterine segment thickness in patients of previous cesarean section. Int $\mathrm{J}$ Obstet Gynecol. 2004 Dec 1;87(3):215-9.

5. Birth After Previous Caesarean Birth, RCOG Greentop Guideline 45 October 2015. Available at: https://www.rcog.org.uk/globalassets/documents/gui delines/gtg_45.pdf.

6. National Institute for Health and Clinical Excellence. Caesarean section. NICE clinical guideline 2011. Available

at: https://www.nice.org.uk/guidance/cg132.

7. Asakura H, Nakai A, Ishikawa G, Suzuki S, Araki T. Prediction of Uterine Dehiscence by Measuring Lower Uterine Segment Thickness Prior to the Onset of Labor. J Nippon Med Sch. 2000;67(5):352-6.

8. Rozenberg P, Goffinet F, Philippe HJ, Nisand I. Ultrasonographic measurement of lower uterine segment to assess risk of defects of scarred uterus. Lancet. 1996;347:281-4.

9. Michaels WH, Thompson HO, Boutt A, Schreiber FR, Michaels SL, Karo JA. Ultrasound diagnosis of defects in the scarred lower uterine segment during pregnancy. Obstet Gynacol. 1988 Jan;71(1):112-20.

10. Cowan RK, Kinch RA, Ellis B, Anderson R. Trial of labor following cesarean delivery. Obstet Gynacol. 1994 Jun;83(6):933-6.

11. Grobman WA. Rates and prediction of successful vaginal birth after cesarean. In Seminars in perinatology. 2010;34(4):244-248.

12. Rosen MG, Dickinson JC. Vaginal birth after cesarean: a meta-analysis of indicators for success. Obstet Gynacol. 1990;77:465-70.

13. Macones GA, Cahill AG, Stamilio DM, Odibo A, Peipert J, Stevens EJ. Can uterine rupture in patients attempting vaginal birth after cesarean delivery be predicted?. Am J Obstet Gynacol. 2006;195(4):114852.

14. Fukuda M, Fukuda K, Mochizuki M. Examination of previous caesarean section scars by ultrasound. Archives Gynecol Obstet. 1988 Dec 1;243(4):221-4. 
15. Sen S, Malik S, Salhan S. Ultrasonographic evaluation of lower uterine segment thickness in patients of previous caesarean section. Int J Gynecol Obstet. 2004;87:215-9.

16. Cheung VYT, Constantinescu OC, Ahluwalia BS. Sonographic evaluation of lower uterine segment in patients with previous caesarean delivery. J Ultrasound Med. 2004;23:1441-7.

17. Gotoh H, Masuzaki H, Yoshida A, Yoshimura S, Miyamura T, shimaru T. Predicting incomplete uterine rupture with vaginal sonography during the late second trimester in women with prior cesarean. Obstet Gynecol. 2000;95:596-600.
18. Qureshi B, Inafuku K, Oshima K, Masamoto H, Kanazawa. Ultrasonographic evaluation of lower uterine segment to predict the integrity and quality of caesarean scar during pregnancy: A prospective study. Tohuku J Exp Med. 1997;183:55-65.

19. Cheung Y. Sonographic measurement of the lower uterine segment thickness: Is it truly predictive of uterine rupture? J Obstet Gynaecol. 2009;113:520.

Cite this article as: Jha NNS, Maheshwari S, Barala S. Ultrasonographic assessment of strength of previous cesarean scar during pregnancy. Int J Reprod Contracept Obstet Gynecol 2018;7:1458-63. 